\title{
Leitura, música e emoção: pesquisa e formação no âmbito do Profletras
}

\section{Reading, music and emotion: research and education in Profletras' field}

\author{
Emiliane Santana Gomes ${ }^{1}$ \\ Nair Floresta Andrade Neta 2
}

DOI: $10.28998 / 2317-9945.2020 n 64 p 76-91$

\section{Resumo}

Neste artigo, objetivamos apresentar alguns dados de uma pesquisa-ação e evidenciar o papel do Profletras na transição da competência implícita à aplicada. Fundamentamo-nos em Almeida Filho (2010), Stenhouse (1993), Ribeiro (2005), Demo (1996, 2003), Freire (1996), Damásio (2000, 2004, 2012), Ekman (2011) e Andrade Neta (2011, 2014). Os resultados sugerem que a tríade leitura, música e emoção contribui para a superação de obstáculos à leitura e à aprendizagem. Assim, identificamos, nessa proposta, seu potencial para contribuir para a produção de conbecimento aplicado à melhoria do ensinoaprendizagem no contexto investigado e para a emergência de uma formação atenta à marcante influencia da afetividade nos processos cognitivos e inter-relacionais. Para tanto, o professor precisa ser pesquisador de sua prática.

Palavras-chave: Profletras. Professor-pesquisador. Afetividade

\begin{abstract}
In this work, we aim to present some data from an action research and highlight the role of Profletras in the transition from implicit to applied competence. We are based on Almeida Filho (2010), Stenhouse (1993), Ribeiro (2005), Demo (1996, 2003), Freire (1996), Damásio (2000, 2004, 2012), Ekman (2011) and Andrade Neta $(2011,2014)$. The results suggest that the triad of reading, music and emotion contributed to overcoming obstacles to reading and learning. Therefore, we identify in this proposal its potential to contribute to the production of knowledge applied to the improvement of the teaching-learning process in the investigated context and to the emergence of an education attentive to to the influence of affectivity in the cognitive and inter-relational processes. For this purpose, the teacher needs to be a researcher of his/ her own practice.
\end{abstract}

Keywords: Profletras. Research professor. Affectivity

Recebido em: 23/03/2018.

Aceito em: 06/07/2018.

\footnotetext{
${ }^{1}$ Graduada em Letras Vernáculas pela Universidade do Estado da Bahia. Mestra pelo Programa de Mestrado Profissional em Letras Profletras/Universidade Estadual de Santa Cruz e professora da Rede Estadual e da Rede Municipal de Itamaraju -BA.

2 Doutora em Didática da Língua e Literatura pela Universidad Complutense de Madrid. Docente da Universidade Estadual de Santa Cruz.
} 


\section{Considerações iniciais}

Os últimos anos, em nosso país, têm sido promissores, quanto às possibilidades de inserção do professor da educação básica em programas de capacitação, inclusive stricto sensu, como o de Mestrado Profissional em Letras (doravante, Profletras), destinado a professores de Língua Portuguesa (doravante, LP) que estão atuando em sala de aula no ensino fundamental. Entre suas aspirações, o Profletras persegue a formação de professores que, estimulados pelo programa, venham a desenvolver e adotar práticas inovadoras em sala de aula, contribuindo, assim, para mudar um pouco o cenário educacional do sistema público de ensino.

Compreender e empreender o processo de ensino-aprendizagem como um ato que se consolida com base na emoção é um desses possíveis caminhos para a inovação em sala de aula, conforme temos constatado com nossa pesquisa de mestrado, na qual procuramos aproximar a tríade leitura, música e emoção, três experiências muito presentes e vivenciadas em sala de aula, mas cuja relação tem sido pouco explorada didática e sistematicamente.

Influenciada pelos avanços das pesquisas acerca da emoção e do sentimento, a afetividade nas práticas pedagógicas tem se tornado também objeto de estudo e pesquisa, sobretudo a partir dos anos 90. Desde então, em conjunto, os resultados dessas investigações vêm demonstrando que a dimensão afetiva marca o sujeito em seu processo de construção de conhecimento, como podemos verificar nos trabalhos de Falcin (2008), Galvão (2003), Grotta (2008), Tassoni (2008), entre outros.

Apesar dessa inseparabilidade entre os processos cognitivos e afetivos na construção do conhecimento, temos constatado a escassez - em alguns casos, a inexistência - de tratamento dos fenômenos afetivos como componente curricular nos cursos de graduação e pós-graduação destinados à formação de professores. Conceitos como emoção, sentimento, prazer, gosto ou paixão comumente são considerados como aspectos muito subjetivos para serem tratados nas escolas e universidades.

No intuito de superação dessa lacuna na formação de professores, o Profletras da Universidade Estadual de Santa Cruz, de forma excepcional em comparação com outros programas e contextos, tem nos propiciado compreender como as emoções, os sentimentos, os desejos, o prazer, a gostatividade intervêm no ensino-aprendizagem. Nesse sentido, tratar da dimensão afetiva na formação humana em um contexto asfixiado pela equivocada oposição entre emoção e razão é, ao nosso ver, uma necessidade e, também, uma prática inovadora para quem nunca a havia experimentado antes, com a consciência alerta acerca de sua incidência, tanto no fazer docente quanto no discente.

Foi nesse contexto de efervescente e profícuo diálogo entre teoria e prática, entre o já vivido e o pretendido, promovido pelo Profletras, que surgiu o projeto de pesquisa, objeto deste trabalho, intitulado Leitura, música e emoção: uma proposta de mediação pedagógica para os anos finais do ensino fundamental, objetivando investigar como o trabalho com o gênero textual música poderia contribuir para a leitura em sala de aula do nono ano e quais seriam as consequências emocionais e cognitivas de tal prática.

3 Aprovado pelo Comitê de Ética e Pesquisa (CEP), no dia 22 de setembro de 2017, sob o parecer de número 2.292.431. Todos os sujeitos envolvidos assinaram o Termo de Assentimento Livre e Esclarecido (TALE), no caso de menores; maiores (ou seus responsáveis) assinaram o Termo de Consentimento Livre e Esclarecido (TCLE). 
Assim, em nossa pesquisa, concebemos o trabalho com a leitura na perspectiva dos gêneros textuais, defendida originalmente por Bakhtin (1997) e adotada pelos PCN (BRASIL, 1997; 1998). Quanto à música, nos fundamentamos teoricamente em Costa (2001, 2002, 2003), Tatit $(2007,2008)$ e Gardner (1995). A pesquisa também integra a afetividade como uma dimensão da prática pedagógica, defendida por autores como Wallon (1968, 1971, 1978, 1995), Vygotsky (1993, 1998), Freire (1996) e Andrade Neta (2008, 2011, 2014, 2015), e considera as emoçôes e os sentimentos de emoção como o fenômeno afetivo, tomando como referência para a sua compreensão autores como Damásio (2000, 2004, 2012), Ekman (2011) e Andrade Neta, García García e Gargallo (2008), e, para a compreensão da mútua influência entre leitura e emocionalidade, nos valemos de Andrade Neta (2008), Andrade Neta e Silva (2005), Grotta (2008) e Leite (2013).

Trata-se de uma pesquisa-ação, com procedimentos de coleta de dados antes, durante e depois da intervenção didática, mediante observação dos participantes, notas de campo, entrevistas semiestruturadas individuais (doravante, EI) e focalizadas de grupo (doravante, EFG), além de questionário avaliativo (doravante, QA) pós-atividade. Para a etapa de intervenção didática, foram elaboradas e aplicadas treze sequências didáticas (doravante, SD) em forma de oficinas pedagógicas, desenvolvidas durante as aulas de LP, com uma turma de 32 alunos de uma escola do município de Itamaraju, no estado da Bahia.

Neste artigo, apresentamos alguns dados da pesquisa supramencionada, desde o seu nascedouro, na sala de aula, fruto de uma prática sustentada pelo que Almeida Filho (2010) chama de competência implícita, até a conversão desse objeto de ensino, na escola, em objeto de pesquisa, na pós-graduação. Pretendemos, assim, evidenciar o relevante papel do Profletras nesse processo de transição da competência implícita à aplicada e na ruptura de um paradigma de ensino que já se mostra obsoleto: o de uma concepção de ensino centrada exclusivamente nos aspectos cognitivos a uma formação atenta à marcante influência da afetividade no processamento cognitivo e nas relações interpessoais que ocorrem em uma instituição de ensino.

Além das considerações iniciais e finais, o artigo está estruturado em três seções: na primeira, trataremos do Profletras como mestrado profissional (doravante, MP), definindo sua origem, expansão e público-alvo; na segunda, defenderemos o papel do programa como um rito de passagem entre a competência implícita e a profissional; na terceira, apresentaremos a pesquisa-ação em si, partindo dos conceitos-chave da pesquisa à discussão dos dados.

Pesquisar sobre a afetividade e desenvolver uma proposta de ensino com base nesse conhecimento têm sido, para nós, uma rica e gratificante experiência de inovação.

\section{O Profletras como mestrado profissional: origem, expansão e público-alvo}

Como se sabe, o mestrado e o doutorado formam pesquisadores e professores para atuarem no âmbito acadêmico, à diferença dos $\mathrm{MP}$, mais voltados à prática profissionalizante. Essa modalidade de formação vem sendo incentivada pela Capes desde 1995, mas demorou um pouco a se expandir, especialmente no âmbito educacional. 
$\mathrm{Na}$ opinião de Cohen (2017, p. 2), o fato de as pessoas estarem buscando "conhecimento aplicado por meio de formação compatível com o exercício profissional está impulsionando a multiplicação dos cursos de mestrado profissional em todo o país". Amparando-se em dados oferecidos pela Coordenação de Aperfeiçoamento de Pessoal de Nível Superior (Capes), acrescenta, ainda, que a quantidade desses programas aumentou muito em seis anos, "saltando de 247 para 703". Segundo a estatística consultada, "em 2010, calculavam-se 247 MP e 1.091 mestrados acadêmicos. Em 2016, a proporção já era de 703 para 1.292, respectivamente" (COHEN, 2017, p. 2).

É nesse contexto que surge o Profletras, um programa de pós-graduação stricto sensu, reconhecido pela Capes, do Ministério da Educação, ofertado em rede nacional, em parceria com 42 instituições de ensino superior públicas, abrangendo 49 unidades. O seu objetivo é capacitar professores de LP para a prática docente no ensino fundamental, a fim de contribuir para a melhoria da qualidade da educação em todo o país (CAPES, 2013). O curso torna viável a capacitação de maior número de professores atuantes, permitindo o diálogo entre o ensino e a pesquisa, a escola e a universidade, transformando a sala de aula em um espaço de experimentação e transposição dos conhecimentos, com potencial para ressignificação da sua prática pedagógica.

A Universidade Estadual de Santa Cruz é uma das instituições de ensino superior que contempla o programa de pós-graduação de MP em Letras, sob a coordenação nacional de uma instituição federal, localizada no nordeste brasileiro. Essa oferta tem possibilitado a formação e obtenção do título de mestre a muitos docentes da área de abrangência dessa instituição, provenientes dos municípios mais próximos, mas, também, de outros localizados no Estado e fora dele. Desde a oferta da primeira turma, em 2014, já foram admitidos ao programa 94 professores-pesquisadores, a maioria já obteve o título de mestre, enquanto outros estão prestes a conquistá-lo. Devido à sua natureza, os MP são programas idôneos para o desenvolvimento de professores-pesquisadores, porque lhes estimulam a transformar sua sala de aula em laboratórios.

O movimento a favor da pesquisa sobre a prática em educação foi encabeçado por Lawrence Stenhouse (1993), a partir da consideração de que o currículo se desenvolve quando o docente também se desenvolve. Nesse sentido, considera-se professorpesquisador, aquele que, na sua prática, ao interferir no projeto pedagógico escolar, teoriza seu fazer, ou seja, produz conhecimentos teóricos que podem ser aplicados em outros contextos de ensino aprendizagem, por outros profissionais.

O trabalho de conclusão de curso dos MP pode ser um produto final, em substituição à convencional dissertação. Não obstante, os trabalhos finais do Profletras costumam ser a dissertação acompanhada de um produto final, na forma de uma proposta de intervenção didática. Muitos desses produtos nascem da prática do professor, em sala de aula, são avaliados ao amparo da teoria e metodologia científicas e retornam, aperfeiçoados, às mãos do(s) professor(es). Nesse processo, o professor torna-se pesquisador de sua prática.

Consoante a Ribeiro (2005, p. 15), o produto final constitui-se como algo muito relevante nos MP; exige-se do professor que durante os estudos concomitantes à sua atuação em sala de aula deva ocorrer também “a imersão na pesquisa [...]”, sobretudo com a finalidade de capacitar o indivíduo para que a utilize "de modo a agregar valor a suas atividades, sejam essas de interesse pessoal ou social". Desse modo, os MP estão a serviço 
da população, pois contribuem positivamente para a pesquisa, devolvendo à sociedade o conhecimento aplicado.

Desse modo, empregando metodologia científica, os mestrandos do Profletras poderão investigar temas associados à sua prática pedagógica, o que lhes permitirá refutar ou corroborar a eficácia de técnicas, procedimentos e atividades utilizados durante anos de experiência, podendo também ressignificar a sua práxis e refletir a respeito desta.

Como nos adverte Demo (2003, p. 10, grifo do autor), "pesquisa pode [e, no caso do professor-pesquisador de sua práxis, deve] significar condição de consciência crítica e cabe como componente necessário de toda proposta emancipatória". Para tanto, sugere que "é preciso construir a necessidade de construir caminhos, não apenas receitas que tendem a destruir o desafio de construção". Esse é o papel que o Profletras pode promover na formação do professor-pesquisador, pois nos desperta essa necessidade de construção de nossos próprios caminhos, em nosso contexto de atuação e formação. Isso nos encaminha à desmistificação da pesquisa, também defendida por Demo (2003), sobrepujando a falsa divisão entre ensino e pesquisa.

\section{Da competência implícita à competência profissional: o Profletras como um rito de passagem}

A educação nas universidades e nas escolas busca conscientizar o indivíduo para uma formação cidadã, a fim de torná-lo um agente transformador do meio em que vive. O problema é que nem todos sabem disso. Nesse sentido, como professores, precisamos entender que abordagem de ensino está orientando a nossa prática e em que medida essa abordagem respeita, atende, converge com a abordagem de aprender de nossos alunos e, ainda, com a abordagem de ensino-aprendizagem imposta pelo livro didático que adotamos. Isso porque, na prática docente, notamos que o nosso desempenho pode carregar muito do que Almeida Filho (2010), ao tratar da formação e atuação de professores de LP como língua estrangeira, chama de competência implícita, aplicada e profissional.

Para esse autor, a abordagem de ensinar está composta por um conjunto de disposições que o professor possui para orientar todas as suas decisões e ações empreendidas para ensinar a língua, que vão do planejamento, passando pela seleção, adequação e/ou produção do material didático a ser utilizado, até a metodologia de ensino e de avaliação. A abordagem é considerada, por Almeida Filho (2010, p. 13), como "uma filosofia de trabalho, um conjunto de pressupostos explicitados, princípios estabilizados ou mesmo crenças intuitivas quanto à natureza da linguagem humana, [...] de aprender e de ensinar línguas, da sala de aula [...] e de papéis [...]”. Mas o aluno também traz para a escola a sua abordagem ou cultura de aprender, que se caracteriza pelas suas concepções e crenças acerca da língua e de sua aprendizagem.

Além das abordagens de ensinar e aprender, que estão em constante tensão, não podemos desconsiderar o que Almeida Filho (2010, p. 13) denomina de "configurações individuais dos filtros afetivos" do aluno e do professor, que envolve motivações, desejos, emoções, sentimentos, interesses, gostos, preferências, bloqueios para aprender. Seguindo essa linha de raciocínio, desenvolvida pelo autor, a abordagem de ensinar do professor varia entre dois extremos, que vão do explícito/conhecido e do implícito/desconhecido. 
Seria conveniente e proveitoso que, gradualmente, como professores, se desse a explicitação de nossa abordagem de ensinar, o que nem sempre ocorre.

Para Stenhouse, “[...] a capacidade de investigar do professor depende de estratégias de auto-observação [...], o que lhe permite utilizar-se a si como instrumento de investigação" (1993 apud DICKEL, 2001, p. 57). Para que esse processo ocorra, é imprescindível que o docente se reconheça como peça fundamental dessa investigação e possa realizar uma autoavaliação acerca da sua própria prática docente - muitas vezes não analisada sob o olhar investigativo - para seu possível aperfeiçoamento.

A explicitação da abordagem depende das competências desenvolvidas pelo professor, que funcionam como matéria-prima de suas concepções. Para compreender esse processo, Almeida Filho (2010) propõe um continuum composto por três níveis de competência. A competência mais básica, que seria a implícita, constituída pelas nossas aprendizagens, seja no papel de alunos, seja no papel de professores, acumulando e reproduzindo experiências confirmadas como (in)eficazes, mas cuja (in)eficácia não somos capazes de explicar. Em um segundo nível, encontra-se a desejável competência aplicada, a que nos capacita a ensinar de acordo com aquilo que sabemos que sabemos. Trata-se de uma prática teoricamente fundamentada, que nos permite explicar por que fazemos o que fazemos em sala de aula e por que (não) obtemos os resultados que (não) obtemos. Embora seja uma competência desejável, a formação do professor não se esgota nessa competência, mas pode alcançar um terceiro patamar de desenvolvimento, o da competência profissional, que nos coloca em um nível superior de consciência e fruição profissional, porque nos permite administrar nosso crescimento como professor, conhecer nossos deveres, direitos, potenciais e relevância social no exercício do magistério.

Segundo a nossa forma de apreciar o impacto do Profletras na formação do professor, uma das contribuições mais relevantes do Programa tem sido a promoção dessa transição que temos feito da competência implícita (baseada na empiria) a uma competência aplicada (com base na teoria) e, por que não dizer, a uma competência profissional também. O Profletras tem nos feito refletir, analisar e avaliar a eficácia do que praticávamos há anos em sala de aula porque obtínhamos bons resultados, mas sem saber como explicá-los.

Nesse sentido, o Profletras funciona como uma espécie de rito de passagem em nossa vida profissional. Não apenas porque nos promove social e profissionalmente, pela concessão do grau de mestre, mas também porque nos ajuda a enxergar a nossa prática com menor ingenuidade e ignorância epistemológica. Todos aqueles que vivem, viveram esse "cair em si" jamais serão os mesmos professores de antes.

A pesquisa-ação que desenvolvemos como trabalho de conclusão de curso, e que será apresentada na próxima seção, é fruto dessa transição da competência implícita à aplicada, e desta, à profissional.

Como defende Almeida Filho (2010), em quem nos baseamos para fundamentar a discussão levantada nesta seção,

para produzir impacto (perceptível), mudanças (profundas) e inovações (sustentadas) não são suficientes alterações apenas no material didático, mobiliário, nas verbalizações do desejável pelas instituições de ensino, nas técnicas renovadas e nos atraentes recursos audiovisuais (ALMEIDA FILHO, 2010, p. 13). 
As verdadeiras e consistentes mudanças nas abordagens de ensino-aprendizagem só ocorrem quando modificamos a matriz que as alimenta, ou seja, as nossas competências, em busca de transformação contínua. Para corroborar essa ideia, passamos a palavra a Freire (1996, p. 29), quando diz: "Ensino porque busco, porque indaguei, porque indago e me indago. Pesquiso para constatar, constatando, intervenho, intervindo educo e me educo. Pesquiso para conhecer o que ainda não conheço e comunicar ou anunciar a novidade". É na busca desse constante refazer que devemos nos propor como professorespesquisadores. Do contrário, não haveria ensino, mas a mera transferência dos saberes acumulados ao longo dos anos de experiência docente.

\section{A pesquisa-ação}

Nesta seção, apresentaremos alguns dados da pesquisa, apresentada, em linhas gerais, nas considerações iniciais. Para tanto, dividiremos essa parte em três subseções. $\mathrm{Na}$ primeira, apresentaremos a metodologia da pesquisa; na segunda, os conceitos-chave da fundamentação teórica acerca da afetividade e da música como gênero textual; e, na terceira, uma breve discussão acerca dos dados da pesquisa, apresentando um avanço dos resultados.

\section{Procedimentos metodológicos}

Procedemos a uma pesquisa-ação, definida como "um tipo de pesquisa com base empírica que é concebida e realizada em estreita associação com uma ação ou com a resolução de um problema coletivo" (THIOLLENT, 1985, p. 14).

A pesquisa foi dividida em quatro etapas, realizadas entre setembro e dezembro de 2017. Os dados foram coletados mediante observação participante, diário de campo, entrevistas semiestruturadas, registros fotográficos, audiogravações, videogravações e questionários avaliativos, analisados com o apoio da análise de conteúdo. Tivemos como cenário da pesquisa a Escola Municipal Professora Maria d'Ajuda Oliveira Mattos, no município de Itamaraju, Bahia, tendo como público-alvo 32 alunos do nono ano. Ao longo do processo, fomos constatando o papel do programa na promoção do professorpesquisador de sua prática, a partir do diálogo entre teoria e prática.

Sobre gostos, emocõos, sentimentos e música na sala de aula: conceitos-chave da pesquisa

Uma das nossas maiores aspirações, como professores de LP, é que os alunos gostem de ler e sintam prazer ao fazê-lo, mas nem sempre sabemos explicar o que é o gosto, o prazer e os fenômenos afetivos a eles relacionados. Nesta seção, nos dedicaremos a apresentar alguns conceitos-chave da pesquisa, no que concerne à afetividade e à música, essenciais à compreensão de sua incidência e influência na sala de aula de LP.

No âmbito educacional, o gosto nos remete aos estudos sobre a gostatividade, neologismo conhecido por nós, a partir da leitura das publicações as quais nos foram apresentadas nas aulas do mestrado, na disciplina "Aspectos sociocognitivos e 
metacognitivos da leitura e escrita". Em suas pesquisas sobre a gostatividade, Andrade Neta $(2011,2014)$ constatou que

a presença da gostatividade exerce uma influência positiva na relação cíclica: professor-ensino-aluno-aprendizagem-língua e sua ausência ou negação interfere nas inter-relações entre os pares do processo de formação [...]. Apesar da relevância desse fenômeno no âmbito educacional, conforme aparece nos estudos revisados, a gostatividade ainda não recebeu a devida atenção científica que merece (ANDRADE NETA, 2011, p. 246; 2014, p. 6, tradução nossa).

A autora também se refere à incidência do gostar docente do que se faz sobre o gostar discente, ratificando a possibilidade dessa espécie de contágio emocional, algo que já havia sido apontado por outros autores, como Jesus (2007), Silva (2002) e Freire (1996). Para Jesus (2007, p. 27), quando o professor "não gosta de ensinar, o aluno percebe esta atitude, podendo diminuir o seu próprio envolvimento no processo de ensinoaprendizagem". Em sua pesquisa sobre emoções e sentimentos na escola, Silva (2002) tratou da confusão que sentem os alunos na hora de discernir entre o gostar do professor e o gostar da matéria por este ministrada, já que quando não gostam do professor, tendem a não gostar da matéria e vice-versa. Freire também se referiu à importância do gostar da docência, ao afirmar: "Não posso desgostar do que faço sob pena de não fazê-lo bem" (1996, p. 67)4.

Damásio (2004) faz uma breve alusão à existência de reações emocionais de origem desconhecida e inconsciente, entre as quais, cita os gostos. Assim, a partir desse pressuposto teórico, Andrade Neta (2011) definiu a gostatividade como "uma reação emocional não deliberada, de origem inconsciente, que se conforma através da aprendizagem, durante o desenvolvimento individual e a qual se manifesta automaticamente com relação a pessoas, grupos, objetos, atividades, lugares e situações cotidianas" (ANDRADE NETA, 2011, p. 246, tradução nossa).

Sabemos que, durante muito tempo, gosto, paixão, emoção, sentimento foram fenômenos considerados excessivamente subjetivos e inferiores para receberem o mesmo reconhecimento que a razão e a cognição, sendo estas atendidas prioritariamente na escola, enquanto aqueles foram relegados a segundo plano e considerados como responsáveis pelo desequilíbrio do ser humano, em momentos em que a racionalidade deveria dominar.

Damásio vem contribuindo com pesquisas que demonstram que as emoções desempenham um importante papel no comportamento do ser humano. Ao situar a emoção como base do processo de desenvolvimento humano, esse autor propõe a reformulação da máxima cartesiana, inovando com o "existo e sinto, logo penso" (DAMÁSIO, 2012, p. 218). Assim, Damásio (2012) pretende evidenciar que as emoções antecederam a razão no desenvolvimento humano e que as estruturas da razão foram edificadas com e sobre as emocionais. Dessa forma, notamos que emoções e cognição são assumidas como dois fenômenos indissociáveis que sempre estiveram, estão e estarão presentes em nossas operações racionais, cognitivas e intelectivas. Quanto ao prazer, Damásio (2000) o situa como desencadeador e constituinte das emoções positivas.

\footnotetext{
${ }^{4}$ Diante de menções dessa natureza e dos resultados de suas pesquisas, Andrade Neta $(2011,2014)$ considera o gosto como um fenômeno afetivo emergente, cuja influência no fazer docente e discente precisa ser melhor elucidada. Para dar-lhe evidência e discerni-lo do gosto ao qual nos referimos sem maiores reflexões, a autora passa a adotar o termo gostatividade. No contexto de sua pesquisa inicial, o gosto foi percebido como uma emoção positiva, no entanto, novas investigações precisam corroborar ou refutar essa hipótese.
} 
Segundo Freire (1996), a educação não pode ser concebida como algo frio, isento de emoções. E, na conjuntura educacional em que nos encontramos, observamos, como professores, que é fundamental reconhecer e lidar com os (des)afetos que se fazem presentes na relação professor-aluno-objeto do conhecimento durante a construção do saber histórico, cultural e social. homens,

Consoante a Paul Ekman, investigador principal da expressão emocional nos

A emoção é um processo, um tipo específico de avaliação automática, influenciado por nosso passado evolucionista e pessoal, em que sentimos que algo importante para nosso bem-estar está acontecendo e um conjunto de mudanças fisiológicas e comportamentos emocionais influenciam a situação (EKMAN, 2011, p. 31).

Tais mudanças influenciam no comportamento do ser humano, favorecendo ou não o sucesso da aprendizagem. No que tange a sentimento, conforme a definição proposta por Damásio, "é uma percepção de um certo estado do corpo, acompanhado pela percepção de pensamentos com certos temas e pela percepção de um certo modo de pensar. Todo esse conjunto perceptivo se refere à causa que lhe deu origem" (DAMÁSIO, 2004, p. 92). Apesar de analisarmos os termos emoção e sentimento de maneira separada, é interessante salientar que os acontecimentos se iniciam no primeiro e continuam no segundo. Trata-se de um continuum. As emoções dão origem aos sentimentos de emoção, que são os registros cognitivos daquelas.

Fazer com que o alunado leia e goste de fazê-lo tem sido um dos maiores desafios encontrados pelos professores nas escolas. Observamos que, se soubermos trabalhar com textos de um modo mais alegre, as aulas podem ser prazerosas, e isso consequentemente pode melhorar o relacionamento aluno-professor, uma vez que estes se sentirão motivados à leitura e à explicação do conteúdo proposto.

Assim, vimos que os estudos acerca da dimensão afetiva, iniciados no MP, entendendo a afetividade como um campo amplo no que se refere às manifestações do ser humano, compreendendo emoções e sentimentos, segundo Wallon (1995), pode favorecer, de modo expressivo, a aprendizagem do aluno, propiciando-lhe uma formação digna e mais harmoniosa. Isso justifica nossa escolha pela música como gênero textual para trabalhar de modo mais afetivo com os nossos alunos.

A canção, como gênero literomusical (COSTA, 2001, p. 334), é um texto que apresenta uma linguagem mais acessível para nossos alunos, facilitando assim a aquisição da leitura e de conhecimentos linguísticos de um modo mais agradável. Por ser de natureza intersemiótica, a música encaixa-se no contexto da pesquisa, visto que, consoante os Parâmetros Curriculares Nacionais (1998), "todo texto se organiza dentro de determinado gênero em função das intenções comunicativas, como parte das condições de produção dos discursos as quais geram usos sociais que os determinam" (BRASIL, 1998, p. 21).

O gênero música, "híbrido" e "de caráter intersemiótico" (COSTA, 2003, p. 18), exige do indivíduo as competências verbal, musical e literomusical, simultaneamente. Já sob a perspectiva afetiva, "A música é um potente evocador de memórias e emoções" (ANDRADE NETA, 2014, p. 2), principalmente positivas. Então, partindo desse entendimento, sendo a música algo de que os alunos já gostam, podemos promover um maior equilíbrio entre cognição e emoção na sala de aula, por meio desse gênero complexo 
e multissensorial tão presente nos ambientes escolares, para a aprendizagem prazerosa do aluno e do ensino prazeroso do professor, que, satisfeito e feliz com a satisfação e a felicidade de seus alunos, tonifica seu bem-estar docente.

\section{Discussão dos dados: o texto literomusical, de objeto de ensino a objeto de pesquisa e ensino}

Durante os encontros, que envolvem o corpo docente dos anos finais do ensino fundamental, escutamos muitas reclamações acerca das dificuldades de leitura, tratadas pelos professores como um problema de natureza, exclusivamente, cognitiva, quando, em realidade, o conteúdo dessas reclamações se refere também à dimensão afetiva, pois parecem estar diretamente relacionadas com a ausência de interesse, de prazer e de gosto pela leitura demonstrada pelo aluno durante as aulas.

Percebemos, no entanto, que este cenário muda quando o alunado está em contato com a música. A partir dessa constatação, como professora de LP, vimos desenvolvendo algumas experiências de leitura em sala, mediante a inserção da letra de música, as quais têm se mostrado muito eficientes, pois isso tem se tornado uma alternativa positiva na construção de uma relação mais afetiva, aproximando aluno, professor e objeto do conhecimento, conforme já antecipamos na introdução.

Ao cursar a disciplina "Aspectos sociocognitivos e metacognitivos da leitura e da escrita", no primeiro semestre do Profletras, na qual tivemos a oportunidade de refletir sobre o componente emocional na/da leitura em trabalhos como os de Andrade Neta e García Garcia (2013), Castro (2002), Grotta (2008) e Larroza (2001), passamos a entender essas experiências prévias associando letra de música e leitura, que vínhamos realizando com base em uma competência implícita, já que, até o momento, não conseguíamos explicar em que consistia o êxito dessa prática, nem qual era o seu real impacto na aprendizagem dos alunos. Nesse sentido, se alguém nos perguntasse sobre a eficiência dessa prática, certamente, nossa resposta se limitaria a dizer que assim atuávamos porque os alunos gostavam e aprendiam mais.

A construção progressiva da competência aplicada nos levou a problematizar nosso fazer, o que deu origem a nosso projeto de pesquisa. Queríamos saber, através da investigação-ação, tendo como participantes do estudo alunos do nono ano, como trabalhar com a música como gênero poderia contribuir para a leitura em sala de aula. Mas nosso interesse não se esgotava nessa verificação. Queríamos saber o que acontece na mente e no coração desses alunos, ao vivenciarem essa experiência de formação, ou seja, quais seriam as consequências emocionais (eles se sentem mais alegres, entusiasmados, interessados, animados, e, por conseguinte, mais motivados e envolvidos nas tarefas?) e cognitivas (percebem maior concentração, atenção, retenção, aprendizagem?) de tal prática.

Após escutarmos, transcrevermos e lermos sistematicamente as entrevistas, as notas de campo e os QA, definimos, com base na interpretação do corpus da pesquisa, as três categorias de análise: gostar de ler, gostar de música e consequências cognitivas e emocionais da aplicação da pesquisa. Na primeira categoria, abordamos a relação afetiva dos alunos com a leitura. Na segunda, a relação afetiva dos participantes com a canção. No que tange à terceira, alterações no comportamento dos alunos desencadeadas a partir da relação afetiva deles com a leitura e com a música. 
Anteriormente à intervenção didática, foram realizadas entrevistas semiestruturadas. Os resultados das EI com relação a essas categorias apontavam a relação afetiva dos alunos com relação ao gosto pela leitura e pela música. Veremos como um dos participantes se referiu às suas percepções com relação a cada categoria analítica:

\section{Antes da intervenção didática}<smiles>[Te]</smiles>

Adoro ler romances, vários outros, lendas, livros bíblicos. As aulas de leitura são ótimas, mas eu quase não participo porque eu sou muito tímida, dá vergonha[...]. Fico com medo de ter que ir lá na frente. Eu começo a tremer de vergonha mesmo. Gosto de ler pra mim só, só comigo e a professora (Nina, 15 anos, EI).

A música seria melhor pra a gente se expressar e conseguir entender [...] A linguagem da música, o tom, o som, o toque, o ritmo (Nina, 15 anos, $\mathrm{EI})$.

Após as EI, coletamos dados que ampliaram e aprofundaram nosso conhecimento acerca das declarações iniciais dos participantes e dos resultados observados nas experiências preliminares. Em seguida, realizamos a intervenção pedagógica, que consistiu na aplicação, seguida de avaliação, de SD a partir do gênero canção. Durante e depois da aplicação da proposta, os dados foram sendo coletados mediante as notas de campo e os QA. Pudemos ir registrando em tempo real e constatamos os seguintes resultados quanto às categorias de análise:

\section{Durante a intervenção didática}<smiles>[Te]</smiles>

A aula foi mais legal que a gente teve a oportunidade de se expressar. [...] Aprendi mais [...] sim, o assunto sobre leitura. [...] eu senti emoção em ler e lembro das coisas do passado. Senti também amor, carinho, amizade [...] alegria. [...] interesse [pela aula de leitura] (Nina, 15 anos, QA).

Eu estou lendo o livro de as mil e uma noites. Eu escrevi tudo o que eu entendi (Nina, 15 anos, notas de campo).

Foi mais legal que a gente teve a oportunidade de se expressar. Aprendi cantar e inventar paródia. [...] a tirar a vergonha e desenvolver [através da] na música. [...] Aprendi mais[...] sim, o assunto, porque eu gosto que envolve a música (Nina, 15 anos, QA).

Posteriormente à intervenção, foi feita uma nova coleta de dados e pudemos notar o quão envolvidos e interessados ficaram os(as) estudantes com o estudo da música como gênero textual nas aulas de LP, tendo como principal objetivo fazer com que o alunado gostasse de ler a partir da utilização desse gênero. Assim, constatamos, mediante os dados registrados nas EFG, os seguintes efeitos:

\section{Depois da intervenção didática}

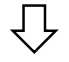

Comecei a querer ler livros, [a] interessar mais pelo estudo da escola. [...] Eu me senti mais alegre, mais animada nas aulas de leitura realizada em sala de aula. E eu gostei também das música (sic) que a gente entende o que se passa no mundo porque nos mostra o que é errado e o que é certo. [...] Na minha opinião, a leitura passou a ser uma tarefa... porque é 
mais fácil a gente realizar ela com o auxilio de uma canção ou de uma letra ou da música. [...] Porque a gente entende melhor, a gente compreende melhor [...] Eu achei que aprendi muito nas atividade (sic) (Nina, 15 anos, EFG).

No geral, as consequências cognitivas identificadas e registradas pelos alunos foram atenção, concentração, aprendizagem, vontade, facilitação cognitiva, práticas leitoras, compreensão e raciocínio. Com relação à sua emocionalidade, os alunos perceberam e reconheceram os benefícios da associação da leitura com a música. Assim, identificamos como as principais consequências emocionais dessa prática: a presença predominante de emoções positivas, como calma, bem-estar e alegria, interesse, distração e relaxamento; além de outros fenômenos, também afetivos, ligados a essas emoções, como maior interesse, prazer, desejo de aprender, gostar de ler, motivação para ler. Isso, portanto, corrobora a prática do que já vínhamos realizando em sala de aula, sendo eficaz promover a leitura a partir da associação com a música e com a emoção.

A partir das declarações supracitadas, corroboramos as nossas expectativas ao associar música, leitura e emoção em um projeto de pesquisa tendo como mediação pedagógica a aplicação de atividades que envolvam aluno-professor-objeto de conhecimento de uma maneira afetiva. Constatamos, então, que a escola como instituição responsável pela formação integral dos cidadãos, como apregoa a Lei de Diretrizes e Base da Educação (BRASIL, 1996), pode considerar o papel dos afetos, das emoções e dos sentimentos, ensinando os seus alunos a manterem o equilíbrio entre emoção e cognição, favorecendo uma aprendizagem prazerosa.

\section{Considerações finais}

Após o projeto ter sido executado, temos corroborado os resultados preliminares à pesquisa, oriundos de uma prática baseada na abordagem implícita, que ganhou outros contornos, podendo ser comprovada com base na aplicação do projeto de pesquisa. Ademais, comprovamos a eficácia da utilização do gênero literomusical para promover a leitura nas aulas de LP e constatamos que esse gênero textual continua se mostrando muito eficiente porque, entre outros fatores, o alunado já traz, como construção anterior, o gosto por música, de modo que reage emocionalmente de forma positiva às atividades que a incluem. Além disso, constatamos também que utilizar a canção como gênero textual favorece uma relação mais afetiva entre aluno, professor e objeto do conhecimento, no contexto investigado. Os participantes demonstraram isso antes, durante e depois da aplicação das SD, durante as oficinas pedagógicas.

Procuramos, ao longo deste artigo, defender, por um lado, o papel do MP, como programa de capacitação docente em serviço, na transição da competência implícita à aplicada, e desta à profissional; por outro, seu papel na interrupção de um paradigma de ensino centrado na consideração exclusiva dos processos da cognição em detrimento dos afetivos, em prol de uma formação que integre essas duas dimensões, sendo que esta última, a dos afetos, tem origem nos gostos, nas motivações e interesses dos alunos para chegar à prática da leitura institucionalizada. Em terceiro lugar, apresentamos alguns dados da pesquisa. 
Esperamos, com este trabalho, divulgar nossa pesquisa, referente ao trabalho de conclusão do mestrado profissional em Letras. Identificamos, nesta proposta, seu potencial para contribuir para a produção de conhecimento aplicado à melhoria do ensinoaprendizagem no contexto investigado, especialmente no que concerne às atividades de leitura. A identificação das consequências cognitivas e emocionais dessa prática indicou-nos como tornar o processo de ensino-aprendizagem da língua portuguesa mais efetivo e prazeroso, favorecendo a construção positiva de uma relação mais afetiva aproximando professor, aluno e objeto do conhecimento.

Diante do exposto, é fundamental a ampliação e adesão das universidades a programas voltados para a formação do professor, para que este possa se envolver em ensino e pesquisa, na produção de conhecimento a fim de transformar a pesquisa em conteúdo de ensino-aprendizagem, com base nas experiências vivenciadas por esses indivíduos. A pesquisa é uma fonte de inspiração para a inovação da prática pedagógica. Portanto, inovar é preciso, mas pesquisar também o é.

\section{Referências}

ANDRADE NETA, N. F. Lectura y emocionalidad: un estudio de la dimensión afectiva de la lectura en LE (Trabajo de Investigación Tutelado para la obtención del DEA). Madri: Universidad Complutense de Madrid, 2008.

ANDRADE NETA, N. F. Emociones y sentimientos en la formación de profesores de Español como Lengua Extranjera. 2011. Tese (Doutorado em Didática da Língua e Literatura) - Universidad Complutense de Madrid, Madri, 2011.

ANDRADE NETA, N. F. Se gosto, gosto. Se não gosto, não gosto. E isso influencia mesmo? Um estudo da dimensão afetiva na formação docente. IV Simpósio Baiano das Licenciaturas/IV Seminário Baiano do Pibid/IAT. Ilhéus, v. 1, p. 1-8, 2014.

ANDRADE NETA, N. F. A música no ensino de línguas estrangeiras modernas na educação básica: orientações didáticas. Projeto de pesquisa do orientador. Título do Projeto: Quem canta, seus males espanta: música, emoções, transversalidade e ensino de línguas estrangeiras modernas. Programa de Iniciação Científica da UESC-ProIC 2014/2015. Ilhéus, 2015.

ANDRADE NETA, N. F.; GARCÍA GARCÍA, E. A influência entre leitura e emocionalidade: um estudo da dimensão afetiva. Ecos de Linguagem, v. 2, p. 153-175, 2013.

ANDRADE NETA, N. F.; GARCÍA GARCÍA, E.; GARGALLO, I. S. A inteligência emocional no âmbito acadêmico: uma aproximação teórica e empírica. Psicologia Argumento, Curitiba, v. 26, n. 52, p. 11-22, jan./mar. 2008. Disponível em: https://periodicos.pucpr.br/index.php/psicologiaargumento/article/download/19807/p df. Acesso em: 17 set. 2018.

ANDRADE NETA, N. F.; SILVA, L. C. Leitura e saúde emocional. IV Congresso Internacional da ABRALIN, Caderno de Resumos. Brasília, 2005. 
ALMEIDA FILHO, J. C. P. Dimensões comunicativas no ensino de línguas. 6 ed. Campinas: Pontes, 2010.

BAKHTIN, M. Os gêneros do discurso. In: BAKHTIN, M. Estética da criação verbal. São Paulo: Martins fontes, 1997.

BRASIL. LDB. Lei no 9.394, de 20 de dezembro de 1996. Lei de Diretrizes e Bases da Educação Nacional. Disponível em:

http://portal.mec.gov.br/seesp/arquivos/pdf/lei9394_ldbn1.pdf. Acesso em: 17 set. 2018.

BRASIL. Secretaria de Educação Fundamental. Parâmetros curriculares nacionais: introdução aos parâmetros curriculares nacionais. Brasília: MEC/SEF, 1997.

BRASIL. Ministério da Educação. Secretaria de Educação Fundamental. Parâmetros curriculares nacionais: terceiro e quarto ciclos do ensino fundamental. Língua Portuguesa. Brasília: MEC/SEF, 1998.

CASTRO, J. S. de. Emoção e memória: reflexões sobre a influência dessa relação na aprendizagem da leitura. Letras de hoje, Porto Alegre, v. 37, n. 2, p. 25-36, jun. 2002.

COHEN, M. Mestrados profissionais crescem no Brasil. Ensino Superior. 3 de outubro de 2017. Disponível em:http://www.revistaensinosuperior.com.br/mestradosprofissionais-crescem-no-brasil/. Acesso em: 17 set. 2018.

COORDENAÇÃO DE APERFEIÇOAMENTO DE PESSOAL DE NÍVEL SUPERIOR. Programa de Mestrado Profissional em Letras (Profletras). 2013. Disponível em: http://capes.gov.br/educacao-a-distancia/profletras. Acesso em: 17 set. 2018.

COSTA, N. B. A produção do discurso lítero-musical brasileiro. 2001. Tese (Doutorado em Linguística Aplicada e Estudos da Linguagem) - Pontifícia Universidade Católica, São Paulo, 2001.

COSTA, N. B. As letras e a letra: o gênero canção na mídia literária. In: DIONISIO, A. P.; MACHADO, A. R.; BEZERRA, M. A. (org.). Gêneros textuais \& Ensino. Rio de Janeiro: Lucerna, 2002, p. 107-121.

COSTA, N. B. Canção popular e ensino da língua materna: o gênero canção nos parâmetros curriculares de língua portuguesa. Linguagem em (Dis)curso, Tubarão, v. 4, n. 1, p. 9-36, jul./dez. 2003.

DAMÁSIO, A. R. O mistério da consciência: do corpo e das emoções ao conhecimento de si. São Paulo: Companhia das Letras, 2000.

DAMÁSIO, A. R. Em busca de Spinosa: prazer e dor na ciência dos sentimentos. Barcelona: Crítica, 2004.

DAMÁSIO, A. R. O erro de Descartes: emoção, razão e o cérebro humano. 3 ed. São Paulo: Companhia das Letras, 2012.

DEMO, Pedro. Educar pela pesquisa. Campinas: Editora Autores Associados, 1996. 
DEMO, Pedro. Pesquisa: princípio científico e educativo. 9 ed. São Paulo: Cortez, 2003.

DICKEL, Adriana. Que sentido há em se falar em professor-pesquisador no contexto atual? Contribuições para o debate. In: GERALDI, Corinta Maria Grisolia; FIORENTINI, Dario et al. Cartografias do trabalho docente: professor(a)-pesquisador(a). Campinas: Mercado Aberto, 2001, p. 33-71.

EKMAN, P. A linguagem das emoções: revolucione sua comunicação e seus relacionamentos reconhecendo todas as expressões das pessoas ao redor. Trad. Carlos Szlak. São Paulo: Lua de papel, 2011.

FALCIN, D. C. Afetividade e condições de ensino: histórias de professores inesquecíveis. In: LEITE, S. A. da S. (org.). Afetividade e práticas pedagógicas. 2 ed. São Paulo: Casa do psicólogo, 2008.

FREIRE. P. Pedagogia da autonomia. São Paulo: Paz \& Terra, 1996.

GALVÃO, I. Expressividade e emoções segundo a perspectiva de Wallon. In: ARANTES, V. A. (org.). Afetividade na escola: alternativas teóricas e práticas. São Paulo: Summus, 2003.

GARDNER, H. Inteligências múltiplas: a teoria na prática. Trad. Maria Adriana Veríssimo Veronese. Porto Alegre: Artes Médicas, 1995.

GROTTA, E. C. B. Constituição do sujeito-leitor: análise de alguns aspectos relevantes. In: LEITE, S. A. S. (org.). Afetividade e práticas pedagógicas. 2 ed. São Paulo: Casa do psicólogo, 2008.

JESUS, Saul N. de. Professor sem stress: realização profissional e bem-estar docente. Porto Alegre: Mediação, 2007.

LARROZA, E. M. J. Leitura: emoção, prazer. 2001. Dissertação (Mestrado em Letras) Universidade Católica de Pelotas, Pelotas, 2001.

LEITE, S. A. da S. (org.). Afetividade e letramento na educação de jovens e adultos EJA. São Paulo: Cortez, 2013.

RIBEIRO, R. J. O mestrado profissional na política atual da Capes. Revista Brasileira de Pós-Graduação, Brasília, v. 2, n. 4, p. 8-15, 2005. Disponível em: http://ojs.rbpg.capes.gov.br/index.php/rbpg/article/view/72/69. Acesso em: 17 set. 2018.

SILVA, L. C. da. Emoções e sentimentos na escola: uma certa dimensão do domínio afetivo. Dissertação (Mestrado em Educação). Ilhéus: Universidade Estadual de Santa Cruz; Univesidade Federal do Sul da Bahia, 2002. Disponível em: http://www.repositorio.ufba.br:8080/ri/bitstream/ri/11773/1/Silva\%2c\%20Lindomar .pdf. Acesso em: 17 set. 2018.

STENHOUSE, L. La investigación como base de la enseñanza. 2 ed. Madrid: Ediciones Morata, 1993. 
TASSONI, E. C. M. Dimensões afetivas na relação professor-aluno. In: LEITE, S. A. da S. (org.). Afetividade e práticas pedagógicas. 2 ed. São Paulo: Casa do psicólogo, 2008.

TATIT, L. A semiótica da canção: melodia e letra. 3 ed. São Paulo: Escuta, 2007.

TATIT, L. A construção do sentido da música na canção popular. In: TATIT, L. Musicando a semiótica: ensaios. 2 ed. São Paulo: Annablume, 2008.

THIOLLENT, M. Metodologia da pesquisa-ação. São Paulo: Cortez, 1985.

VYGOTSKY, L. S. Pensamento e linguagem. São Paulo: Martins Fontes, 1993.

VYGOTSKY, L. S. O desenvolvimento psicológico na infância. São Paulo: Martins Fontes,1998.

WALLON, H. A evolução psicológica da criança. Lisboa: Edições 70, 1968.

WALLON, H. As origens do caráter da criança. São Paulo: Difusão europeia do Livro, 1971.

WALLON, H. Do acto ao pensamento. Lisboa: Moraes Editores, 1978.

WALLON, H. As origens do caráter na criança. São Paulo: Nova Alexandria, 1995. 